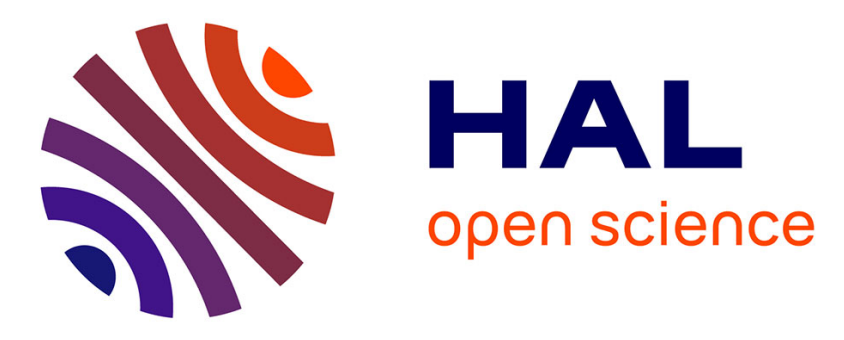

\title{
Pulsed laser deposited amorphous chalcogenide and alumino-silicate thin films and their multilayered structures for photonic applications
}

Petr Němec, Joël Charrier, Michel Cathelinaud, Mathieu Allix, Jean-Luc Adam, Xianghua Zhang, Virginie Nazabal

\section{To cite this version:}

Petr Němec, Joël Charrier, Michel Cathelinaud, Mathieu Allix, Jean-Luc Adam, et al.. Pulsed laser deposited amorphous chalcogenide and alumino-silicate thin films and their multilayered structures for photonic applications. Thin Solid Films, 2013, 539, pp.226-232. 10.1016/j.tsf.2013.04.013 . hal00878948

HAL Id: hal-00878948

https://hal-univ-rennes1.archives-ouvertes.fr/hal-00878948

Submitted on 31 Oct 2013

HAL is a multi-disciplinary open access archive for the deposit and dissemination of scientific research documents, whether they are published or not. The documents may come from teaching and research institutions in France or abroad, or from public or private research centers.
L'archive ouverte pluridisciplinaire HAL, est destinée au dépôt et à la diffusion de documents scientifiques de niveau recherche, publiés ou non, émanant des établissements d'enseignement et de recherche français ou étrangers, des laboratoires publics ou privés. 


\title{
Pulsed laser deposited amorphous chalcogenide and alumino-silicate thin films and their multilayered structures for photonic applications
}

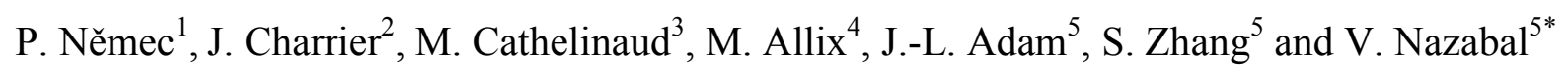

${ }^{1}$ Department of Graphic Arts and Photophysics, Faculty of Chemical Technology, University of Pardubice, Studentská 573, 53210 Pardubice, Czech Republic

${ }^{2}$ FOTON, UMR CNRS 6082, Enssat, 6 rue de Kerampont, BP 80518, 22305 Lannion, France

${ }^{3}$ Missions des Ressources et Compétences Technologiques, UPS CNRS 2274, 92195 Meudon, France

${ }^{4}$ CEMHTI-CNRS, Site Haute Température, Orléans, France

${ }^{5}$ Equipe Verres et Céramiques, UMR-CNRS 6226, Sciences Chimiques de Rennes (SCR), Université de Rennes 1, 35042 Rennes Cedex, France

\begin{abstract}
Amorphous chalcogenide and alumino-silicate thin films were fabricated by the pulsed laser deposition technique. Prepared films were characterized in terms of their morphology, chemical composition, and optical properties. Multilayered thin film stacks for reflectors and vertical microcavities were designed for telecommunication wavelength and the window of atmosphere transparency (band II) at $1.54 \mu \mathrm{m}$ and $4.65 \mu \mathrm{m}$, respectively. Bearing in mind the benefit coming from the opportunity of an efficient wavelength tuning or, conversely, to stabilize the photoinduced effects in chalcogenide films as well as to improve their mechanical properties and/or their chemical durability, several pairs of materials from pure chalcogenide layers to chalcogenide/oxide layers were investigated. Different layer stacks were fabricated
\end{abstract}


in order to check the compatibility between dissimilar materials which can have a strong influence on the interface roughness, adhesion, density, homogeneity, for instance. Three different reflector designs were formulated and tested including all-chalcogenide layers $\left(\mathrm{As}_{40} \mathrm{Se}_{60} / \mathrm{Ge}_{25} \mathrm{Sb}_{5} \mathrm{~S}_{70}\right)$ and mixed chalcogenide-oxide layers ( $\mathrm{As}_{40} \mathrm{Se}_{60} /$ alumino-silicate and $\mathrm{Ga}_{10} \mathrm{Ge}_{15} \mathrm{Te}_{75} /$ alumino-silicate). Prepared multilayers showed good compatibility between different material pairs deposited by laser ablation despite the diversity of chemical compositions. $\mathrm{As}_{40} \mathrm{Se}_{60} /$ alumino-silicate reflector showed the best parameters; its stop band ( $\mathrm{R}>97 \%$ at $8^{\circ}$ off-normal incidence) has a bandwidth of $\sim 100 \mathrm{~nm}$ and it is centered at 1520 $\mathrm{nm}$, thus in good agreement with calculated value. The quality of the different mirrors developed was good enough to try to obtain a microcavity structure for the $1.5 \mu \mathrm{m}$ telecommunication wavelength made of chalcogenide layers. The microcavity structure consists of $\mathrm{Ga}_{5} \mathrm{Ge}_{20} \mathrm{Sb}_{10} \mathrm{~S}_{65}$ (doped with 5000 ppm of $\mathrm{Er}^{3+}$ ) spacer surrounded by two 10-layer $\mathrm{As}_{40} \mathrm{Se}_{60} / \mathrm{Ge}_{25} \mathrm{Sb}_{5} \mathrm{~S}_{70}$ reflectors. Scanning and transmission electron microscopies showed a good periodicity, great adherence and smooth interfaces between the alternating dielectric layers confirming a suitable compatibility between the different materials.

PACS Codes: 68.65.Ac, 78.66.Jg, 81.15.Fg

Key words: Amorphous materials; Pulsed laser deposition, thin films, multilayers 


\section{Introduction}

Recently, new functionality of dielectrics thin films (based on their quarter wave stacks) in the field of omnidirectional reflection (near unity reflectance for all incidence angles/polarization states over a finite spectral region) was recognized [1]. The omnidirectional reflection properties are mainly dependent on two parameters: the refractive index contrast $n_{H} / n_{L}$ - refractive indices ratio of the layers of high and low refractive index, and on the ratio of the lower refractive index to the homogeneous medium surrounding the last layers of the stack $n_{L} / n_{A}\left(n_{A}=1\right.$ for air) leading to a photonic band diagram [2]. It was shown that one of the key prerequisite facilitating omnidirectional reflection is: 1) sufficiently high refractive index contrast $(>0.8)$ between the two materials forming thin film stack and 2) high optical transmission of individual materials in wavelength range of interest $[1,3]$. Due to their suitable properties, amorphous chalcogenide multilayer stacks themselves or combined with low refractive index materials can satisfy mentioned criteria when designing omnidirectional mirrors for infrared region of the spectra. To date, several groups have reported attempts of multilayer stacks fabrication for omnidirectional reflection exploiting combination of a chalcogenide with a polymer $[1,2,4,5]$, or with a fluoride [6-8], or combination of two amorphous chalcogenides [9-12]. It should be noted that other material combinations (requiring usually high-temperature or sophisticated processing) were already proposed, for example $\mathrm{Si} / \mathrm{SiO}_{2}$ [13], $\mathrm{SiO}_{2} / \mathrm{TiO}_{2}$ [14], AlInN/GaN [15], etc. Omnidirectional reflection opens up not only possibility of making mirrors, but also filters or microcavity structures consisting of a spacer layer enveloped by reflecting faces; such structures could play an important role in applications as vertical-cavity surface emitting lasers, microcavity light-emitting diodes, Fabry-Perot modulators, etc. 
In principle, depicted multilayered structures can be generally obtained by different thin films deposition techniques as metal-organic vapor phase epitaxy [15], sol-gel $[14,16]$, radio frequency sputtering [13], thermal evaporation or spin coating/thermal evaporation [4, 5, 8-12]. We already reported pulsed laser deposition (PLD) as a thin films fabrication technique viable for the amorphous chalcogenides as well as alumino-silicates being advantageous due to its simplicity, easy control of the process, often stoichiometric transfer of target material to the films, and possibility to fabricate multilayered structures [17-20]. However, the PLD has a drawback (compared to other deposition techniques such as thermal evaporation) of more difficult control in terms of deposition rate reproducibility; on the other hand it has the advantage of depositing luminescent layers. Fluorescence has many practical applications in chemical and biological detection and analysis because of its great selectivity of fluorescent marks and specificity of radiative emissions. When higher level of sensitivity is demanded, the efficiency of detection becomes crucial. In this case, the utilization of 1D photonic band gap optical structure should be considered aiming at increasing the ability of fluorescence excitation and collection.

Photoinduced changes of optical properties are characteristic of chalcogenide films. The importance of developing multilayers studied in this paper is to play and control the photoinduced effects. Post processing by irradiation of the multilayers consisting of chalcogenides films allows obtaining spatially uniform or structured mirrors, microcavity or filters [6, 21-23]. In order to counteract mentioned problem of deposition rate reproducibility or to have the opportunity of an efficient wavelength tuning or, conversely, to stabilize the photoinduced effects in chalcogenide films, we test several pairs of materials from pure chalcogenide layers to chalcogenide/oxide layers. In the case of the use of alumino-silicates, 
the photosensitivity and photoexpansion of the multilayer structure can be expected to be reduced [24]. The combination of the oxide films with the chalcogenides can also play an advantageous role in the mechanical properties as well as their chemical durability against aging in natural atmosphere $[23,25]$. The difficulty of synthesizing optically homogeneous oxychalcogenides, whether in the form of bulk glass or thin films, could be bypassed by providing optical components based on superimposed oxide and chalcogenide layers.

Hence, the aim of this work is to manifest the preparation of amorphous thin films and their multilayered stacks based on chalcogenides and alumino-silicates by use of PLD technique. In addition to the fabrication of chalcogenide and chalcogenide/alumino-silicate mirrors, the manufacture of all-chalcogenide microcavity for $1.5 \mu \mathrm{m}$ telecommunication wavelength (doped with erbium) was attempted. The main objective is to investigate the feasibility of such multilayers by PLD before assessing in the further study the influence of irradiation. Studied combination of materials could easily be transposed to the field of mid-IR since chalcogenide layers will be transparent in this spectral domain and allow the rare earth emission in this spectral range; that is why a simulation evaluating the suitability of allchalcogenide microcavity for $4.65 \mu \mathrm{m}$ atmosphere transparency window was performed.

\section{Experimental details}

The amorphous thin films and multilayered structures were fabricated using 1) bulk chalcogenide glasses (25 mm diameter slabs) with nominal composition of $\mathrm{Ge}_{25} \mathrm{Sb}_{5} \mathrm{~S}_{70}$, $\mathrm{Ga}_{5} \mathrm{Ge}_{20} \mathrm{Sb}_{10} \mathrm{~S}_{65}$ (doped with $5000 \mathrm{ppm}$ of $\mathrm{Er}^{3+}$ ), $\mathrm{As}_{40} \mathrm{Se}_{60}, \mathrm{Ga}_{10} \mathrm{Ge}_{15} \mathrm{Te}_{75}$ and 2) aluminosilicate hot-pressed targets. Bulk chalcogenide glasses were synthesized in silica ampoules from high-purity elements (typically $99.999 \%$ purity) by melt-quenching method. The 
alumino-silicate targets were prepared from commercial kaolin at temperature of $1100^{\circ} \mathrm{C}$ and pressure of $40 \mathrm{MPa}$, in a carbon matrix.

For the fabrication of multilayered structures as well as single thin films, PLD was employed using above described targets. All depositions of single films and multilayered structures were carried out on silicon substrates. PLD setup consists of a KrF excimer laser (248 nm, 300 $\pm 3 \mathrm{~mJ}$ per pulse, $30 \mathrm{~ns}$ pulse duration, $20 \mathrm{~Hz}$ repetition rate) and vacuum chamber (background pressure $<3 \times 10^{-4} \mathrm{~Pa}$ ). The substrates used for PLD (chemically cleaned microscope glass slides, Si wafers) were positioned parallel to the target surface at the target to substrate distance of $5 \mathrm{~cm}$. The energy fluency on the target was changing with deposited

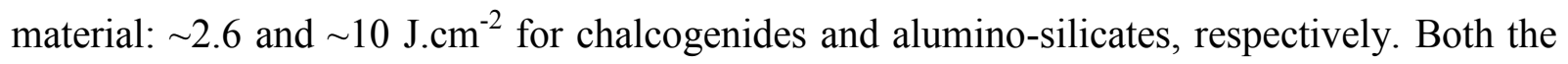
target and the substrates were rotated in off-axis geometry in order to avoid deep damage of the targets and to improve the thickness homogeneity of the films. Prepared films/structures did not undergo any thermal treatment; for subsequent measurements they were used in asdeposited state.

We made different attempts to fabricate reflectors and microcavity for near infrared spectral region. Before doing this, required thicknesses of single layers were approximated applying refractive indices of used targets. After preparation and characterization of single thin films with suitable thicknesses, multilayered structures were prepared using sequential PLD runs. For the estimation of necessary thicknesses $\left(d_{i}\right)$ of individual layers of the reflector stacks, we used refractive index data $\left(n_{i}\right)$ of single layers at $\lambda$ which corresponds to the center of reflection band of the prepared quarter-wave stack at normal incidence. Then, the reflectance spectra were simulated using a transfer matrix method. Transfer Matrix Formalism was applied to calculate the reflectance of an electromagnetic wave across the multilayered 
structure simulating the vertical microcavity._In each zone, the wave-function is completely determined by two scalar components; therefore it can be represented as a bi-dimensional (2D) column vector. The linearity of the electromagnetism equations makes possible to relate the components between any two given abscissae $z$ under a $(2 \times 2)$ matrix form [3]. The transfer matrix of the whole structure is readily expressed as the matrix product:

$[T]=\left[\begin{array}{ll}T_{11} & T_{12} \\ T_{21} & T_{22}\end{array}\right]=\left[I_{a i r, 1}\right]\left(\prod_{i=1}^{n-1}\left[M_{i}\right]\left[I_{i, i+1}\right]\right)\left[M_{i+1}\right]\left[I_{i+1, S i}\right]$,

where the notation (i) corresponds to the $i$ horizontal. Further in Eq. (1), $\left[I_{i ; i+1}\right]$ is the matrix corresponding to the wave propagation across the interface between $i$ and $i+1$ media and $\left[M_{i}\right]$ is the propagation matrix in the $i$ medium.

Reflectance is then given by the equation below

$$
R=\left|\frac{T_{21}}{T_{11}}\right|^{2}
$$

In this model, the dispersion of the refractive index of the individual layers to obtain multilayered structures based on chalcogenides (alumino-silicates) was taken into consideration.

We prepared three different reflector design layer stacks: 1) all-chalcogenide 13-layers $\mathrm{As}_{40} \mathrm{Se}_{60}$ (high-index)/ $\mathrm{Ge}_{25} \mathrm{Sb}_{5} \mathrm{~S}_{70}$ (low index) structure, 2) 13-layers $\mathrm{As}_{40} \mathrm{Se}_{60}$ (high-index)/ alumino-silicate (low-index) structure, and 3) 13-layers $\mathrm{Ga}_{10} \mathrm{Ge}_{15} \mathrm{Te}_{75}$ (high-index)/aluminosilicate (low-index) structure, the latter exploiting larger refractive index contrast. Microcavity 
structure consists of $\mathrm{Ga}_{5} \mathrm{Ge}_{20} \mathrm{Sb}_{10} \mathrm{~S}_{65}$ (doped with 5000 ppm of $\mathrm{Er}^{3+}$ ) spacer surrounded by two 10-layer $\mathrm{As}_{40} \mathrm{Se}_{60} / \mathrm{Ge}_{25} \mathrm{Sb}_{5} \mathrm{~S}_{70}$ reflectors.

The surfaces of the single chalcogenide films as well as alumino-silicate films were studied via scanning electron microscopy (SEM, JEOL JSM 6400) connected with energydispersive X-ray analyzer (EDX). A transverse section of the sample was prepared perpendicular to the thin film surface to allow imaging the stacking of the different layers. The sampling was made by a Philips 200TEM Focused Ion Beam employing Ga ions beam. The section has then been deposited onto a holey carbon film, supported by a copper grid. Imaging studies were then carried out with a Philips CM20 Transmission Electron Microscope (TEM) operating at $200 \mathrm{kV}$ and Field Electron Gun Scanning Electron Microscope Carl ZEISS SUPRA 55 working at $5 \mathrm{kV}$.

Optical functions (real and imaginary parts of dielectric function, refractive indices, and extinction coefficients) and thicknesses of PLD layers and starting bulk glasses were obtained from the analysis of spectroscopic ellipsometry data measured using an ellipsometer with automatic rotating analyzer (VASE, J. A. Woollam Co., Inc.). The measurement parameters are as follows: spectral region 300-2300 nm (i.e. 4.13-0.54 eV) with wavelengths steps of $10-20 \mathrm{~nm}$, angles of incidence $50^{\circ}, 60^{\circ}$, and $70^{\circ}$ in case of glass substrates, eventually $65^{\circ}, 70^{\circ}$, and $75^{\circ}$ in case of silicon substrates. As we were only focused on transparency region of the spectra of prepared films, VASE data were analyzed by a simple model consisting of description of the substrate, the film (employing Cauchy dispersion formula for refractive index, i.e. $n=A+B / \lambda^{2}+\mathrm{C} / \lambda^{4}$, where $n$ is refractive index, $A, B$ and $C$ are constants, $\lambda$ is the wavelength and considering only weak Urbach absorption or setting extinction coefficient to zero) and the surface roughness layer (defined using an effective 
medium approximation). Reflectivity spectra of multilayered structures were recorded with a spectrophotometer (Perkin-Elmer) equipped with reflectance accessory tool in the spectral region of 900-2200 $\mathrm{nm}$. The pump source used for luminescence measurements of $\mathrm{Ga}_{5} \mathrm{Ge}_{20} \mathrm{Sb}_{10} \mathrm{~S}_{65}: \mathrm{Er}^{3+}$ bulk glass was a CW Ti:Sapphire laser operating at $804 \mathrm{~nm}$. Emission spectra were recorded using an InGaAs photodiode and an InSb photodiode cooled with liquid nitrogen and were calibrated by using a tungsten-halogen lamp source and a heat source with emission spectra similar to a black-body source.

\section{Results and discussion}

The thin films and their stacks fabricated by PLD were found to be amorphous and homogeneous according to optical and electron microscopy. The morphology of single layers is of good quality as confirmed by SEM (Fig. 1); we observed only rarely droplets on the surface of the films (with diameter of $\sim 0.01-2 \mu \mathrm{m}$ ) which generally represents a weak point for any PLD film. No other defects, cracks or inhomogeneities were found which could compromise the quality of the interfaces between the different layers.

The chemical composition of the films, as determined by SEM-EDX, is summarized in Table I. Generally, we observe good agreement between chemical composition of target and corresponding single layers in case of $\mathrm{As}_{40} \mathrm{Se}_{60}, \mathrm{Ga}_{10} \mathrm{Ge}_{15} \mathrm{Te}_{75}$, and alumino-silicate. In case of $\mathrm{Ge}_{25} \mathrm{Sb}_{5} \mathrm{~S}_{70}$ and $\mathrm{Ga}_{5} \mathrm{Ge}_{20} \mathrm{Sb}_{10} \mathrm{~S}_{65}$ (doped with 5000 ppm of $\mathrm{Er}^{3+}$ ) samples, their single layers are sulfur deficient. This is consistent with larger values of layers refractive indices when compared with parent targets (Table I).

Figure 2 shows refractive indices spectral dependencies for all the single films under study. It should be noted that extinction coefficient of the layers is close to zero in $700-2300$ 
nm spectral region as expected and confirmed by VASE, excluding $\mathrm{Ga}_{10} \mathrm{Ge}_{15} \mathrm{Te}_{75}$ which shows slight absorption from $\sim 1500 \mathrm{~nm}$ (extinction coefficient below 0.02). The PLD films refractive index contrast at $1540 \mathrm{~nm}$ was found to be 0.45 and 1.12 for $\mathrm{As}_{40} \mathrm{Se}_{60} / \mathrm{Ge}_{25} \mathrm{Sb}_{5} \mathrm{~S}_{70}$ and $\mathrm{As}_{40} \mathrm{Se}_{60}$ /alumino-silicate pairs, respectively, showing the latter as very promising for targeted application. The highest refractive index contrast at $1540 \mathrm{~nm}$ is observed for $\mathrm{Ga}_{10} \mathrm{Ge}_{15} \mathrm{Te}_{75}$ /alumino-silicate pairs, reaching 1.98 .

To illustrate our experimental work, some examples of SEM micrographs of prepared multilayered structures (Bragg mirrors) are presented in Fig. 3. These micrographs reveal strong contrast between the alternate layers of the mirror corresponding to the refractive index contrast. The interfaces between individual layers as well as the surfaces of the multilayered structures were found to be smooth without any defect documenting applicability of PLD for the fabrication of thin film stacks.

We have chosen to manufacture two Bragg reflectors centered at 1520 and $1270 \mathrm{~nm}$ with different reflection bandwidths by taking the index contrast into account. The experimental and theoretical reflectance spectra for the two Bragg mirrors are illustrated in Fig. 4. The two Bragg mirrors were constituted by 13-layered of $\mathrm{As}_{40} \mathrm{Se}_{60}$ and alumino-silicate or $\mathrm{Ge}_{25} \mathrm{Sb}_{5} \mathrm{~S}_{70}$ stacks. The characteristics of Bragg reflector fabrication formed by 13 layers are shown in Table 2. The period is formed by two layers of high and low indices (respectively $H I$ and $L I$ ). Each layer is characterized by its refractive index $n$ and its thickness $d$.

The Bragg reflector is characterized by its central wavelength $\lambda_{0}$ (at normal incidence) and by the reflection bandwidth $\Delta \lambda$ which is determined mainly by the index contrast. These two parameters are defined by relationships (3) and (4).

$$
\lambda_{0}=2\left(n_{H I} d_{H I}+n_{L I} d_{L I}\right)
$$




$$
\begin{gathered}
\Delta \lambda=\frac{2 \lambda_{0} \Delta \mathrm{n}}{\pi \mathrm{n}}, \\
\text { with } \quad \Delta n=n_{H I}-n_{L I} \\
n=\frac{n_{H I}+n_{L I}}{2} .
\end{gathered}
$$

In Eq. (5), $n_{H I}$ and $d_{H I}$ are the refractive index and the thickness for the layer of higher refractive index, respectively. Accordingly, $n_{L I}$ and $d_{L I}$ stand for the refractive index and the thickness for the layer of lower refractive index, respectively. Finally, the maximum reflectance of Bragg mirror is given by

$$
R=\frac{\left[\left(\frac{n_{L I}}{n_{H I}}\right)^{2 N}-1\right]^{2}}{\left[\left(\frac{n_{L I}}{n_{H I}}\right)^{2 N}+1\right]^{2}},
$$

where $N$ is the number of periods.

The experimental reflectance spectra are in relatively good agreement with the theoretical ones (Fig. 4). The two Bragg reflectors centered at about $1490 \mathrm{~nm}$ and $1310 \mathrm{~nm}$ respectively were well-elaborated by 13-layered $\mathrm{As}_{40} \mathrm{Se}_{60} /$ alumino-silicate or $\mathrm{As}_{40} \mathrm{Se}_{60} / \mathrm{Ge}_{25} \mathrm{Sb}_{5} \mathrm{~S}_{70}$ PLD films stacks. With above mentioned equations, the central wavelength and the reflection bandwidth of two Bragg reflectors were calculated and reported in Table II. A shift of the experimentally observed central wavelength from calculated values could be noticed (Fig. 4, Table II.). This fact would have its origin in both, deviations in refractive indices and/or exact thicknesses of individual layers required for such structures.

Following encouraging results obtained with Bragg mirrors, the last studied optical structure is the vertical microcavity. The microcavity was made up of $\mathrm{Ga}_{5} \mathrm{Ge}_{20} \mathrm{Sb}_{10} \mathrm{~S}_{65}$ (doped 
with $5000 \mathrm{ppm}$ of $\mathrm{Er}^{3+}$ ) spacer surrounded by two reflectors consisted by 10-layer $\mathrm{As}_{40} \mathrm{Se}_{60} / \mathrm{Ge}_{25} \mathrm{Sb}_{5} \mathrm{~S}_{70}$ reflectors. Table III shows the characteristics of the microcavity and the used Bragg reflectors. Some SEM and TEM micrographs of vertical microcavity are presented in Fig. 5. The TEM micrograph reveals a smooth interface between the layers without any defect formed during the fabrication of thin film stacks.

Experimental and simulated reflectance spectra of the microcavity consisted by $\mathrm{Er}^{3+}-$ doped $\mathrm{Ga}_{5} \mathrm{Ge}_{20} \mathrm{Sb}_{10} \mathrm{~S}_{65}$ spacer surrounded by two 10 -layer $\mathrm{As}_{40} \mathrm{Se}_{60} / \mathrm{Ge}_{25} \mathrm{Sb}_{5} \mathrm{~S}_{70}$ reflectors are illustrated by Figures 5c and 6. Fig. 6 shows also fluorescence spectra measured from $\mathrm{Er}^{3+}$ doped $\mathrm{Ga}_{5} \mathrm{Ge}_{20} \mathrm{Sb}_{10} \mathrm{~S}_{65}$ bulk glass. Among the rare earths, erbium was selected as several radiative transitions in near- and mid-IR can be observed in chalcogenide glasses [26, 27]. Recorded fluorescence spectra exhibit two emissions; the maxima of first and second emission bands are located at $\sim 1540$ and $\sim 1710 \mathrm{~nm}$, respectively. Described fluorescence is caused by ${ }^{4} \mathrm{I}_{13 / 2} \rightarrow{ }^{4} \mathrm{I}_{15 / 2}$ and ${ }^{4} \mathrm{I}_{9 / 2} \rightarrow{ }^{4} \mathrm{I}_{13 / 2}$ radiative electron transitions of $\mathrm{Er}^{3+}$ ions [28]. The microcavity was thus designed for ${ }^{4} \mathrm{I}_{13 / 2} \rightarrow{ }^{4} \mathrm{I}_{15 / 2}$ transition emitting at $\sim 1540 \mathrm{~nm}$. Measured cavity central wavelength is located at $1484 \mathrm{~nm}$, thus it is shifted $56 \mathrm{~nm}$ from calculated value of $1540 \mathrm{~nm}$. Reflectance band ( $>95 \%$ ) is occupying $\sim 1345-1590 \mathrm{~nm}$ range, thus it is again blue-shifted from expected values. Mentioned discrepancies could have their origin in both, deviations in refractive indices and/or exact thicknesses of individual layers required for such structure as already discussed in case of reflectors. However, we believe that this work has demonstrated that it is possible to produce a Bragg reflector and a microcavity in the NIR spectral range of amorphous chalcogenide and alumino-silicate thin films by using pulsed laser deposition.

It should be noted that one of the advantages of chalcogenide thin films is their broad transparency window covering mid-IR part of the spectra. We suppose that a microcavity for 
mid-IR range based on $\mathrm{Er}^{3+}$-doped $\mathrm{Ga}_{5} \mathrm{Ge}_{20} \mathrm{Sb}_{10} \mathrm{~S}_{65}$ spacer surrounded by two 10-layer reflectors made of chalcogenides films can be elaborated by physical deposition methods as their compatibility were demonstrated for near-IR. As an example, Fig. 7 is given, where a microcavity centered at $4650 \mathrm{~nm}$ was simulated considering layer thicknesses of 432, 512, and $929 \mathrm{~nm}$ for $\mathrm{As}_{40} \mathrm{Se}_{60}, \mathrm{Ge}_{25} \mathrm{Sb}_{5} \mathrm{~S}_{70}$, and $\mathrm{Er}^{3+}$-doped $\mathrm{Ga}_{5} \mathrm{Ge}_{20} \mathrm{Sb}_{10} \mathrm{~S}_{65}$, respectively. We note that the choice of microcavity central wavelength corresponds with the peak of the fluorescence spectra (Fig. 7) attributed to ${ }^{4} \mathrm{I}_{9 / 2} \rightarrow{ }^{4} \mathrm{I}_{11 / 2}$ transitions of $\mathrm{Er}^{3+}$ ions in $\mathrm{Ga}_{5} \mathrm{Ge}_{20} \mathrm{Sb}_{10} \mathrm{~S}_{65}$ bulk glasses [28].

\section{Conclusions}

We have demonstrated that pulsed laser deposited amorphous chalcogenide $\left(\mathrm{Ge}_{25} \mathrm{Sb}_{5} \mathrm{~S}_{70}, \mathrm{As}_{40} \mathrm{Se}_{60}, \mathrm{Ga}_{10} \mathrm{Ge}_{15} \mathrm{Te}_{75}\right.$, and $\mathrm{Er}^{3+}$-doped $\left.\mathrm{Ga}_{5} \mathrm{Ge}_{20} \mathrm{Sb}_{10} \mathrm{~S}_{65}\right)$ and alumino-silicate thin films can be used for the fabrication of high quality vertical Bragg reflectors or microcavities. The chalcogenide multilayers can help to explore the mid-IR spectral range giving privileged place to the photosensitivity of these components while the chalcogenideoxide mixed multilayers can be interesting for limiting the effects of photosensitivity or making them more specific, playing with the expansion coefficient and allowing enough great versatility in terms of refractive index contrast. Several other structures based on chalcogenide films can be envisaged for a large range of wavelengths; they can be advantageously exploited by exalting the actives properties such as rare earth doped chalcogenide film luminescence or chalcogenide thin films non-linear properties of the defect layer in the periodic structure. 


\section{Acknowledgements}

This work was supported by Czech Science Foundation (project No. P106/11/0506) and a CNRS PICS (International Scientific Cooperation Project). The authors would like to acknowledge F.-X. Lefevre from the CRISMAT laboratory (Caen, France) for SEM imaging.

\section{References}

[1] R.G. DeCorby, N. Ponnampalam, H.T. Nguyen, T.J. Clement, Adv. Mater. 19/2 (2007) 193.

[2] Y. Fink, J.N. Winn, S.H. Fan, C.P. Chen, J. Michel, J.D. Joannopoulos, E.L. Thomas, Science 282/5394 (1998) 1679.

[3] S.H. Kim, C.K. Hwangbo, Applied Optics 41/16 (2002) 3187.

[4] R.G. DeCorby, H.T. Nguyen, P.K. Dwivedi, T.J. Clement, Opt. Express 13/16 (2005) 6228 .

[5] T.J. Clement, N. Ponnampalam, H.T. Nguyen, R.G. DeCorby, Opt. Express 14/5 (2006) 1789.

[6] W.D. Shen, M. Cathelinaud, M. Lequime, F. Charpentier, V. Nazabal, Opt. Express 16/1 (2008) 373.

[7] D.N. Chigrin, A.V. Lavrinenko, D.A. Yarotsky, S.V. Gaponenko, Journal of Lightwave Technology 17/11 (1999) 2018.

[8] M. Zenou, A. Bruner, S.Y. Goldin, M. Klebanov, V. Lyubin, B. Sfez, IEEE Photonics Technol. Lett. 19/21-24 (2007) 1810.

[9] M. Yaman, H.E. Kondakci, M. Bayindir, Opt. Express 18/3 (2010) 3168.

[10] R. Todorov, J. Tasseva, T. Babeva, K. Petkov, J. Phys. D-Appl. Phys. 43/50 (2010) 505103.

[11] T. Kohoutek, J. Orava, J. Prikryl, J. Mistrik, T. Wagner, M. Frumar, Opt. Mater. 32/1 (2009) 154.

[12] H.E. Kondakci, M. Yaman, O. Koylu, A. Dana, M. Bayindir, Appl. Phys. Lett. 94/11 (2009) 111110.

[13] H.Y. Lee, H. Makino, T. Yao, A. Tanaka, Appl. Phys. Lett. 81/24 (2002) 4502.

[14] K.M. Chen, A.W. Sparks, H.C. Luan, D.R. Lim, K. Wada, L.C. Kimerling, Appl. Phys. Lett. 75/24 (1999) 3805.

[15] J.F. Carlin, C. Zellweger, J. Dorsaz, S. Nicolay, G. Christmann, E. Feltin, R. Butte, N. Grandjean, Phys. Status Solidi B-Basic Solid State Phys. 242/11 (2005) 2326.

[16] R.M. Almeida, S. Portal, Current Opinion in Solid State \& Materials Science 7/2 (2003) 151.

[17] P. Nemec, S. Zhang, V. Nazabal, K. Fedus, G. Boudebs, A. Moreac, M. Cathelinaud, X.-H. Zhang, Opt. Express 18/22 (2010) 22944.

[18] P. Nemec, A. Moreac, V. Nazabal, M. Pavlista, J. Prikryl, M. Frumar, J. Appl. Phys. 106/10 (2009) 103509. 
[19] P. Nemec, V. Takats, A. Csik, S. Kokenyesi, J. Non-Cryst. Solids 354/52-54 (2008) 5421.

[20] P. Nemec, V. Nazabal, J. Vavra, J.P. Guin, D. Vesely, A. Kalendova, M. Allix, S. Zhang, C. Drasar, Thin Solid Films 519/4 (2010) 1341.

[21] V. Nazabal, M. Cathelinaud, W. Shen, P. Nemec, F. Charpentier, H. Lhermite, M.-L. Anne, J. Capoulade, F. Grasset, A. Moreac, S. Inoue, M. Frumar, J.-L. Adam, M. Lequime, C. Amra, Appl. Opt. 47/13 (2008) C114.

[22] W. Shen, M. Cathelinaud, M. Lequime, V. Nazabal, X. Liu, Opt. Commun. 281/14 (2008) 3726.

[23] M. Cathelinaud, V. Nazabal, F. Charpentier, J.L. Adam, K. Fedus, G. Boudebs, M. Chauvet, G. Fanjou, K.P. Huy, T. Billeton, S.P. Gorza, W.D. Shen, Chinese optics letters 8 (2010) 1.

[24] S. Charnovycha, P. Nemec, V. Nazabal, A. Csik, M. Allix, G. Matzen, S. Kokenyesi, Mater. Chem. Phys. 130 (2011) 1022.

[25] F. Charpentier, M. Dussauze, M. Cathelinaud, G. Delaizir, E.I. Kamitsos, J.L. Adam, B. Bureau, V. Nazabal, J. Alloys Compd. 509/27 (2011) 7330.

[26] T. Schweizer, D.J. Brady, D.W. Hewak, Opt. Express 1/4 (1997) 102.

[27] J.S. Sanghera, L.B. Shaw, I.D. Aggarwal, Comptes Rendus Chimie 5/12 (2002) 873.

[28] V. Moizan, V. Nazabal, J. Troles, P. Houizot, J.L. Adam, J.L. Doualan, R. Moncorge, F. Smektala, G. Gadret, S. Pitois, G. Canat, Opt. Mater. 31/1 (2008) 39. 


\section{TABLE CAPTION}

Table I. Nominal/real chemical composition of targets as well as PLD single thin films estimated by SEM-EDX and refractive indices at $1.54 \mu \mathrm{m}$ (determined via VASE). For a comparison, bulk data for refractive indices are also shown.

Table II. Characteristics of Bragg reflector fabrication formed by a period repeated $\mathrm{N}$ times. The period is formed by two layers of high and low refractive indices ( $H I$ and $L I)$. Each layer is characterized by its refractive index $n$ (at $\lambda_{0}$ ) and its thickness $d$.

Table III. (a) and (b) Characteristics of microcavity (b) constituted by two Bragg mirrors (a) and one defect layer that separates the two Bragg mirrors. The defect layer is characterized by its refractive index $n$ and thickness $L$. Other symbols have the same meaning as in Table II. 


\begin{tabular}{|c|c|c|c|c|c|c|c|c|c|c|c|}
\hline \multirow[t]{2}{*}{ Norminal composition } & \multirow[b]{2}{*}{ As } & \multicolumn{9}{|c|}{$\begin{array}{c}\text { Real composition (at.\%) } \\
( \pm 0.5 \%)\end{array}$} & \multirow[t]{2}{*}{$\begin{array}{c}\mathrm{n} \\
( \pm 0.01)\end{array}$} \\
\hline & & $\mathrm{Ga}$ & $\mathrm{Ge}$ & $\mathrm{Sb}$ & $\mathrm{S}$ & $\mathrm{Se}$ & $\mathrm{Te}$ & $\mathrm{Al}$ & $\mathrm{Si}$ & $\mathrm{O}$ & \\
\hline \multicolumn{12}{|l|}{ Target } \\
\hline $\mathrm{As}_{40} \mathrm{Se}_{60}$ & 37 & & & & & 62.8 & & & & & 2.83 \\
\hline $\mathrm{Ge}_{25} \mathrm{Sb}_{5} \mathrm{~S}_{70}$ & & & 23.3 & 5.0 & 71.7 & & & & & & 2.13 \\
\hline $\mathrm{Ga}_{5} \mathrm{Ge}_{20} \mathrm{Sb}_{10} \mathrm{~S}_{65}+\mathrm{Er}$ & & 4.6 & 18.7 & 9.5 & 67.2 & & & & & & 2.24 \\
\hline $\mathrm{Ga}_{10} \mathrm{Ge}_{15} \mathrm{Te}_{75}$ & & 10.0 & 14.9 & & & & 75.1 & & & & 3.61 \\
\hline alumino-silicate & & & & & & & & 16.8 & 21.3 & 61.9 & - \\
\hline \multicolumn{12}{|l|}{ Single film } \\
\hline $\mathrm{As}_{40} \mathrm{Se}_{60}$ & 38.6 & & & & & 61.4 & & & & & 2.73 \\
\hline $\mathrm{Ge}_{25} \mathrm{Sb}_{5} \mathrm{~S}_{70}$ & & & 30.3 & 8.6 & 61.1 & & & & & & 2.29 \\
\hline $\mathrm{Ga}_{5} \mathrm{Ge}_{20} \mathrm{Sb}_{10} \mathrm{~S}_{65}+\mathrm{Er}$ & & 6.7 & 23.0 & 15.0 & 55.3 & & & & & & 2.51 \\
\hline $\mathrm{Ga}_{10} \mathrm{Ge}_{15} \mathrm{Te}_{75}$ & & 11.2 & 15.6 & & & & 73.2 & & & & 3.61 \\
\hline alumino-silicate & & & & & & & & 18.5 & 22.3 & 59.2 & 1.62 \\
\hline
\end{tabular}


Table 2

\begin{tabular}{cccccccc}
\hline \hline Name & $\boldsymbol{n}_{\boldsymbol{H I}}$ & $\boldsymbol{d}_{\boldsymbol{H I}}$ & $\boldsymbol{n}_{L I}$ & $\boldsymbol{d}_{L I}$ & $\boldsymbol{N}$ & $\lambda_{0}$ & $\Delta \lambda$ \\
& & $(\mathbf{n m})$ & & $(\mathbf{n m})$ & & $(\mathbf{n m})$ & $(\mathbf{n m})$ \\
\hline Bragg a & 2.73 & 153.4 & 1.624 & 209.2 & 6.5 & 1516 & 489 \\
Bragg b & 2.75 & 122.2 & 2.299 & 129.9 & 6.5 & 1270 & 172 \\
\hline \hline
\end{tabular}


Table 3

(a)

\begin{tabular}{ccccccc}
\hline \hline Name & $n_{H I}$ & $\begin{array}{c}\boldsymbol{d}_{\boldsymbol{H}} \\
(\mathbf{n m})\end{array}$ & $\boldsymbol{n}_{\boldsymbol{L I}}$ & $\begin{array}{c}\boldsymbol{d}_{\boldsymbol{L I}} \\
(\mathbf{n m})\end{array}$ & $\boldsymbol{N}$ & $\begin{array}{c}\lambda_{0} \\
(\mathbf{n m})\end{array}$ \\
\hline Bragg c & 2.73 & 141 & 2.29 & 168 & 5 & 1540 \\
\hline \hline
\end{tabular}

(b)

\begin{tabular}{ccccc}
\hline Name & $\begin{array}{c}\text { Bragg } \\
\text { reflector }\end{array}$ & $\boldsymbol{N}_{1}=\boldsymbol{N}_{2}$ & $\boldsymbol{n}$ & $\begin{array}{c}\boldsymbol{L} \\
(\mathbf{n m})\end{array}$ \\
\hline Cavity 1 & Bragg c & 5 & 2.51 & 306 \\
\hline \hline
\end{tabular}




\section{FIGURE CAPTION}

Fig. 1. SEM micrographs of single thin films: $140 \mathrm{~nm} \mathrm{As}_{40} \mathrm{Se}_{60}$ (a), $165 \mathrm{~nm} \mathrm{Ge}{ }_{25} \mathrm{Sb}_{5} \mathrm{~S}_{70}$ (b), $318 \mathrm{~nm} \mathrm{Ga} \mathrm{Ge}_{20} \mathrm{Sb}_{10} \mathrm{~S}_{65}$ doped with $5000 \mathrm{ppm}$ of $\mathrm{Er}^{3+}$ (c), $247 \mathrm{~nm}$ alumino-silicate (d), and $169 \mathrm{~nm} \mathrm{Ga}{ }_{10} \mathrm{Ge}_{15} \mathrm{Te}_{75}$ (e). Thicknesses were determined from VASE data analysis.

Fig. 2. Refractive indices spectral dependencies (estimated by VASE, error in determination of $n \pm 0.01$ ) for PLD single thin films.

Fig. 3. SEM images of parts of two Bragg mirrors constituted by 13-layered $\mathrm{As}_{40} \mathrm{Se}_{60}$ /alumino-silicate (a) or $\mathrm{As}_{40} \mathrm{Se}_{60} / \mathrm{Ge}_{25} \mathrm{Sb}_{5} \mathrm{~S}_{70}$ (b) thin films stacks.

Fig. 4. Theoretical (a) and experimental (b) reflectance spectra (non-polarized light) measured at $8^{\circ}$ off-normal incidence of two Bragg mirrors constituted by 13-layered $\mathrm{As}_{40} \mathrm{Se}_{60}$ /aluminosilicate (a) or $\mathrm{As}_{40} \mathrm{Se}_{60} / \mathrm{Ge}_{25} \mathrm{Sb}_{5} \mathrm{~S}_{70}$ (b) stacks.

Fig. 5. SEM and TEM micrographs (cross sections) of PLD multilayered structures: SEM (a) and TEM (b) of microcavity consisting of $\mathrm{Ga}_{5} \mathrm{Ge}_{20} \mathrm{Sb}_{10} \mathrm{~S}_{65}$ (doped with 5000 ppm of $\mathrm{Er}^{3+}$ ) spacer surrounded by two 10-layer $\mathrm{As}_{40} \mathrm{Se}_{60}-\mathrm{Ge}_{25} \mathrm{Sb}_{5} \mathrm{~S}_{70}$ reflectors. Experimental (measured at $8^{\circ}$ from normal incidence) reflectance spectrum (non-polarized light) of the microcavity structure is shown in panel (c).

Fig. 6. Simulated reflectance spectrum (non-polarized light, at $8^{\circ}$ from normal incidence) of microcavity structure consisting of $\mathrm{Ga}_{5} \mathrm{Ge}_{20} \mathrm{Sb}_{10} \mathrm{~S}_{65}$ (doped with 5000 ppm of $\mathrm{Er}^{3+}$ ) spacer surrounded by two 10-layer $\mathrm{As}_{40} \mathrm{Se}_{60}-\mathrm{Ge}_{25} \mathrm{Sb}_{5} \mathrm{~S}_{70}$ reflectors: dashed and dotted curves are for spectra simulated with the use of refractive indices of bulk glasses and single layers, 
respectively. Full curve shows fluorescence spectrum measured from bulk $\mathrm{Ga}_{5} \mathrm{Ge}_{20} \mathrm{Sb}_{10} \mathrm{~S}_{65}$ glass doped with $5000 \mathrm{ppm}$ of $\mathrm{Er}^{3+}$ in corresponding spectral range.

Fig. 7. Simulated (at $8^{\circ}$ from normal incidence) reflectance spectrum (dotted curve) of microcavity structure consisting of $\mathrm{Ga}_{5} \mathrm{Ge}_{20} \mathrm{Sb}_{10} \mathrm{~S}_{65}$ (doped with 5000 ppm of $\mathrm{Er}^{3+}$ ) spacer surrounded by two 10-layer $\mathrm{As}_{40} \mathrm{Se}_{60}-\mathrm{Ge}_{25} \mathrm{Sb}_{5} \mathrm{~S}_{70}$ reflectors. The reflectance minimum is centered at $4650 \mathrm{~nm}$. The simulation was performed with the use of refractive indices of single PLD layers. Full curve shows fluorescence spectrum measured from bulk $\mathrm{Ga}_{5} \mathrm{Ge}_{20} \mathrm{Sb}_{10} \mathrm{~S}_{65}$ glass doped with $5000 \mathrm{ppm}$ of $\mathrm{Er}^{3+}$ in corresponding spectral range. 
Click here to download high resolution image

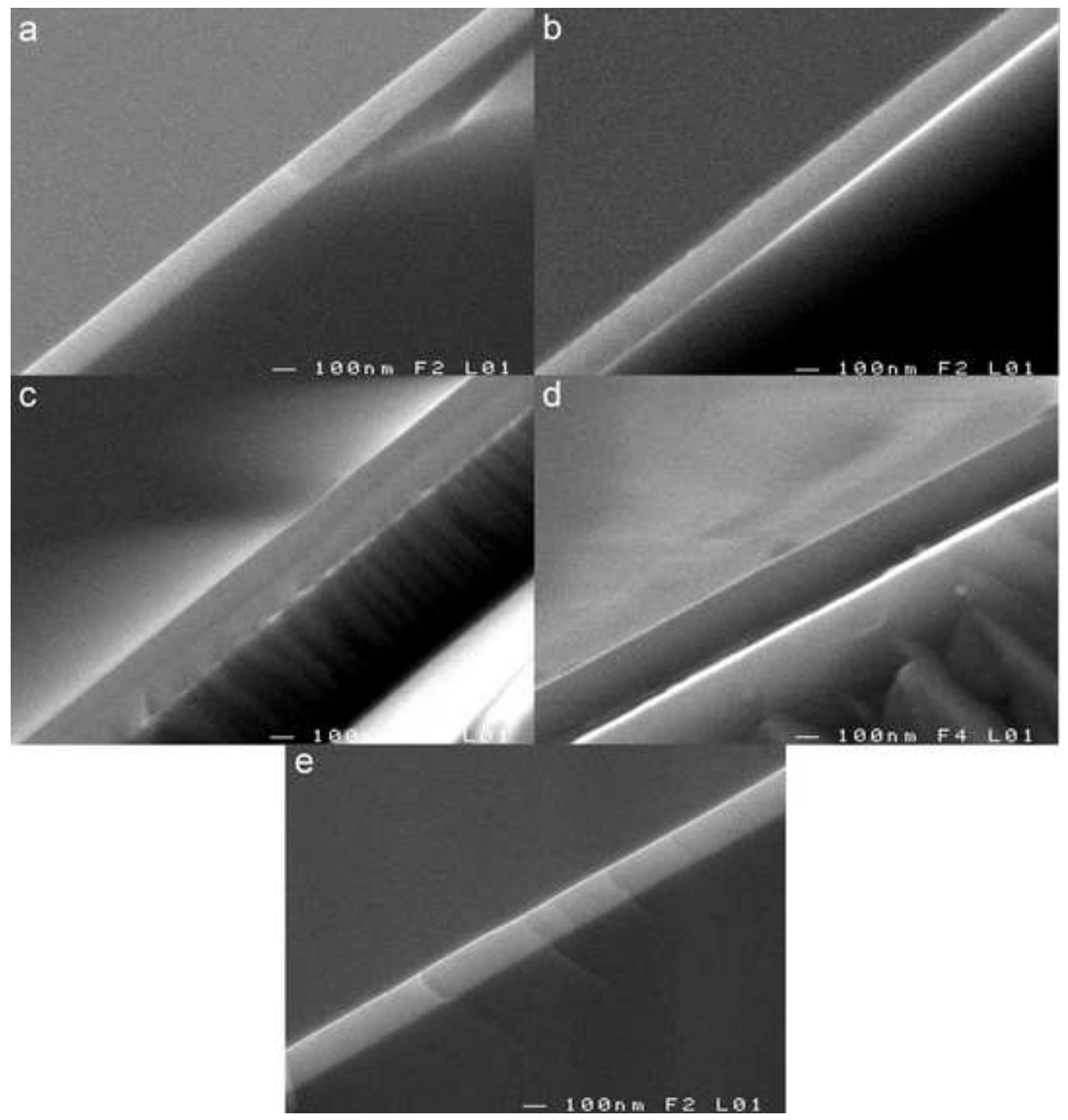




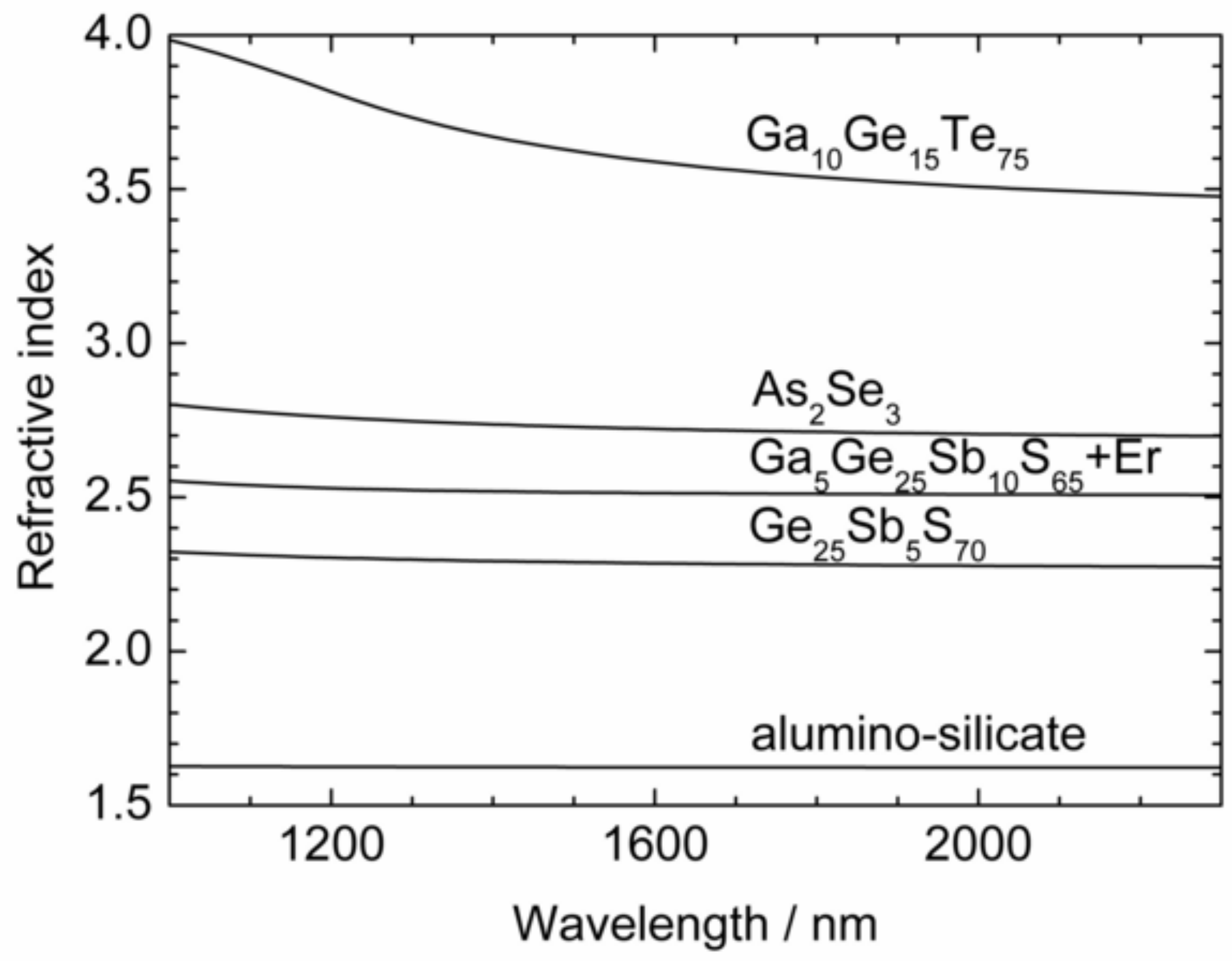




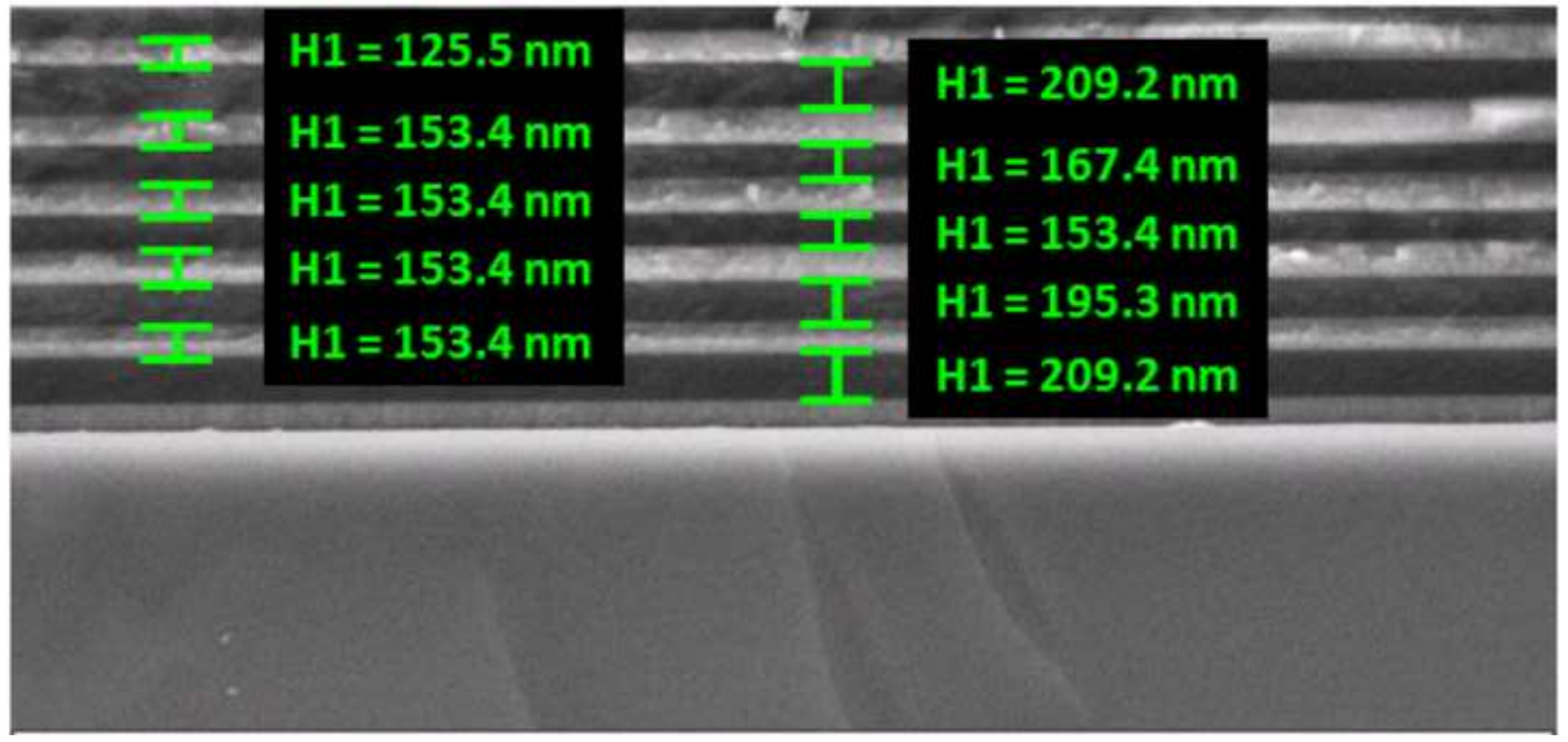

\section{$\mathrm{H} 1=125.5 \mathrm{~nm}$ $\mathrm{H} 1=153.4 \mathrm{~nm}$ $\mathrm{H} 1=153.4 \mathrm{~nm}$ $\mathrm{H} 1=153.4 \mathrm{~nm}$ $\mathrm{H} 1=153.4 \mathrm{~nm}$}

\section{$\mathrm{H} 1=209.2 \mathrm{~nm}$} $\mathrm{H} 1=167.4 \mathrm{~nm}$ $\mathrm{H} 1=153.4 \mathrm{~nm}$ $\mathrm{H} 1=195.3 \mathrm{~nm}$ $\mathrm{H} 1=209.2 \mathrm{~nm}$ 


\section{$\mathrm{H} 1=122.2 \mathrm{~nm}$}

\section{$\mathrm{H} 1=129.9 \mathrm{~nm}$}

\section{$\mathrm{H} 1=129.9 \mathrm{~nm}$}

$\mathrm{H} 1=122.2 \mathrm{~nm}$

$$
\mathrm{H} 1=122.2 \mathrm{~nm}
$$

$$
\mathrm{H} 1=122.2 \mathrm{~nm}
$$

$$
\mathrm{H} 1=122.2 \mathrm{~nm}
$$

$\mathrm{H} 1=122.2 \mathrm{~nm}$

$\mathrm{H} 1=129.9 \mathrm{~nm}$ 


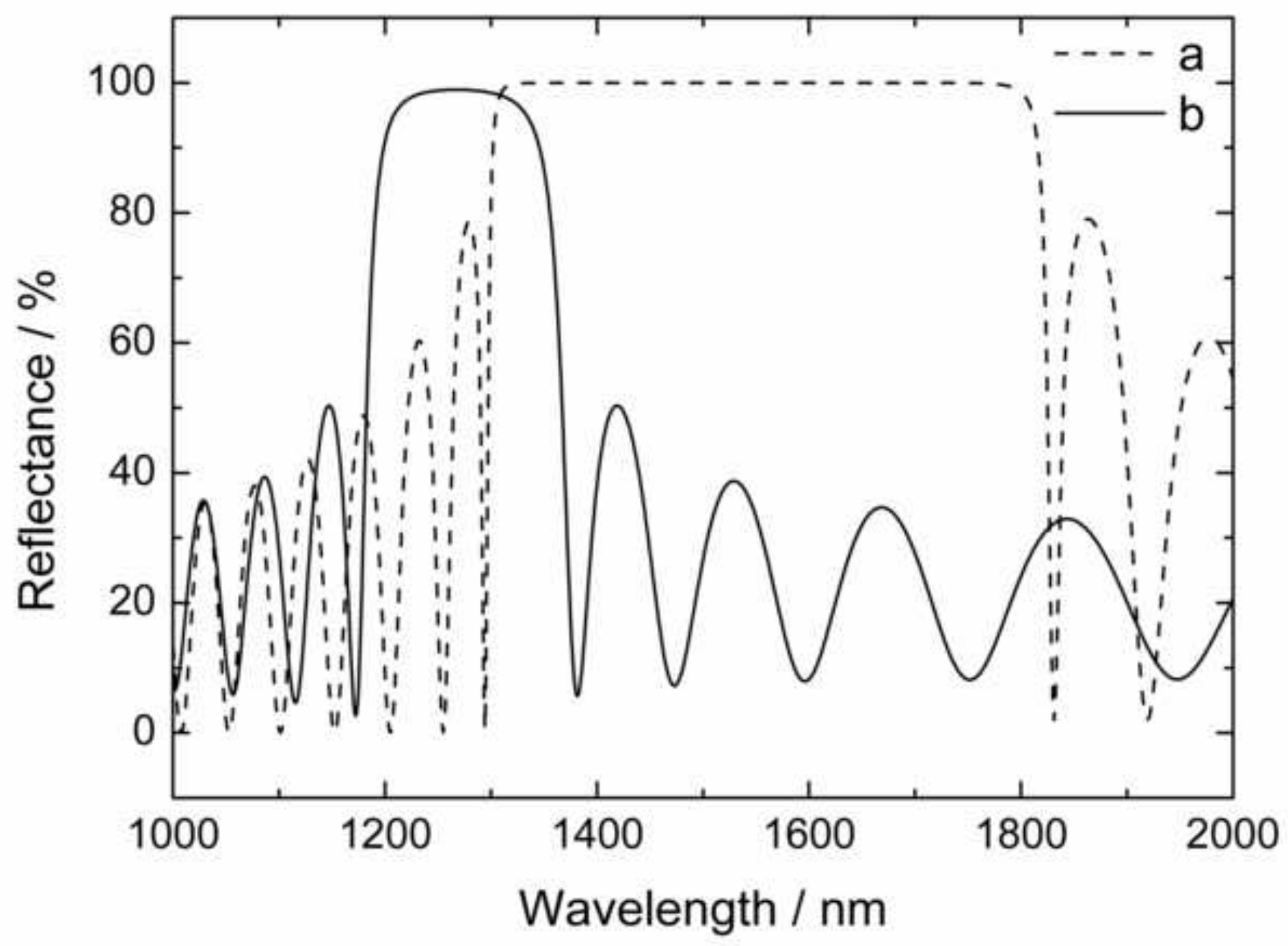




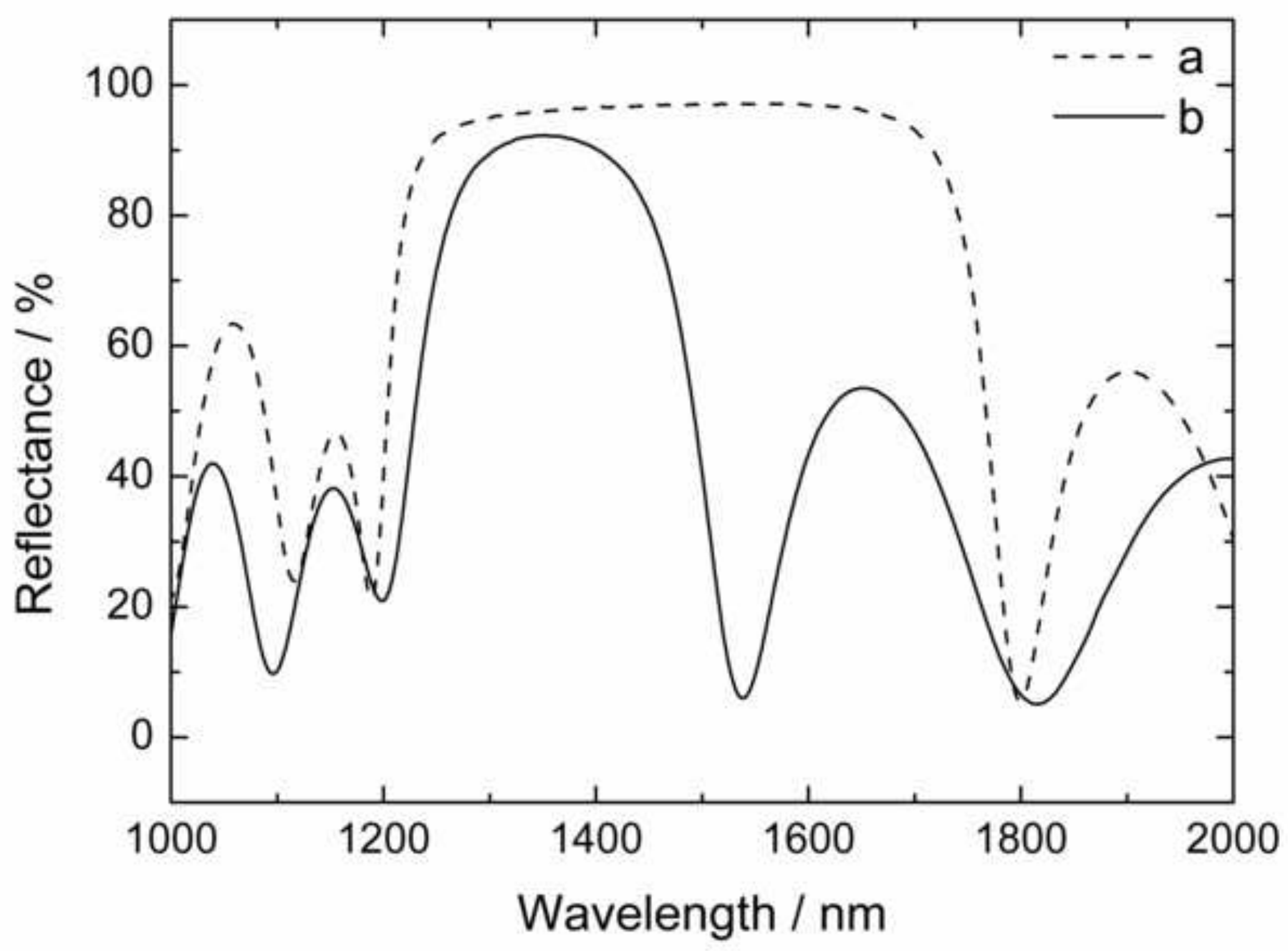


Click here to download high resolution image

\section{$2 \mu \mathrm{m}$}

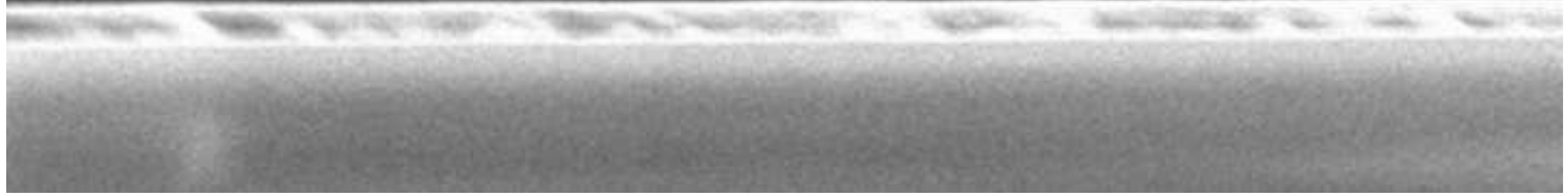




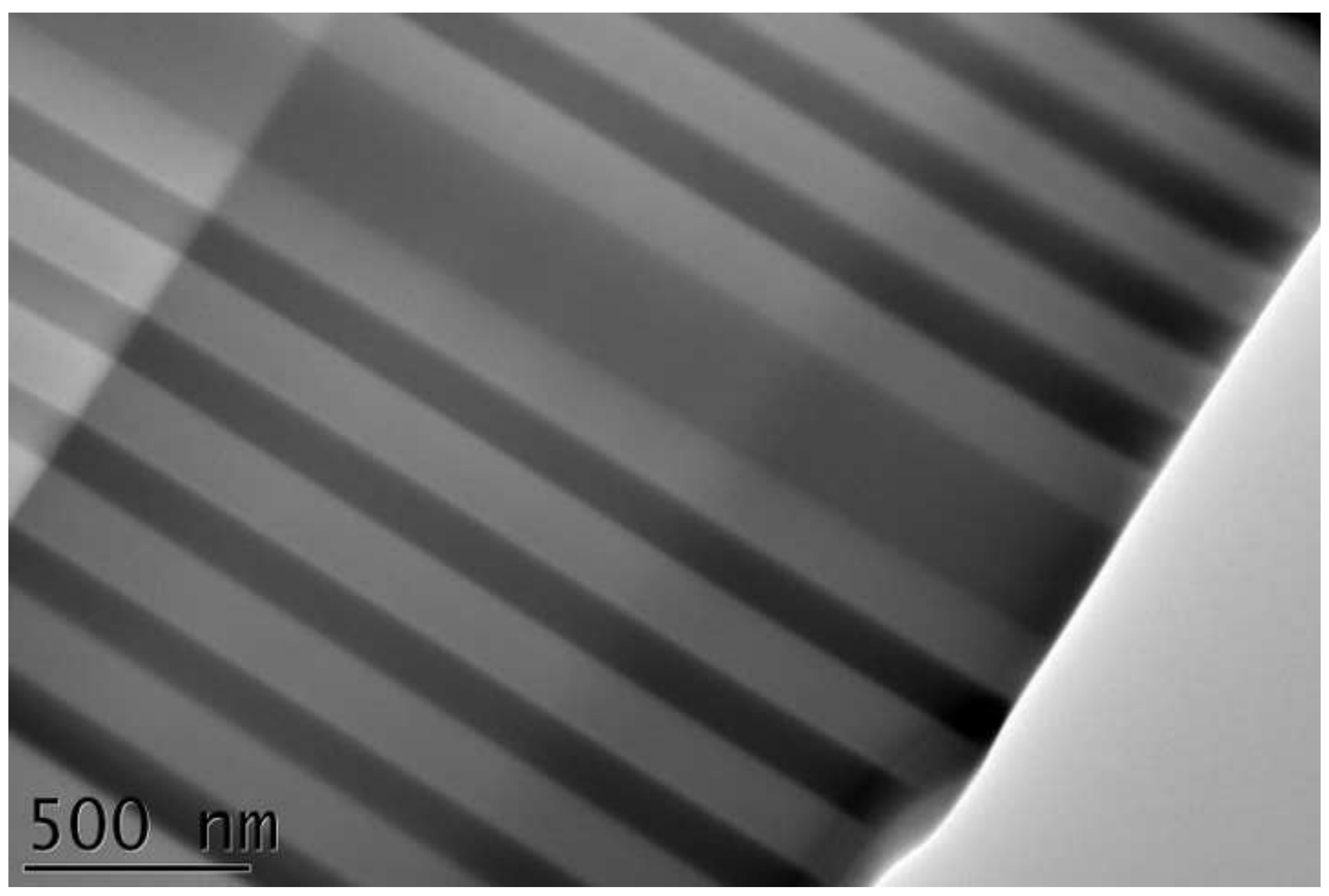




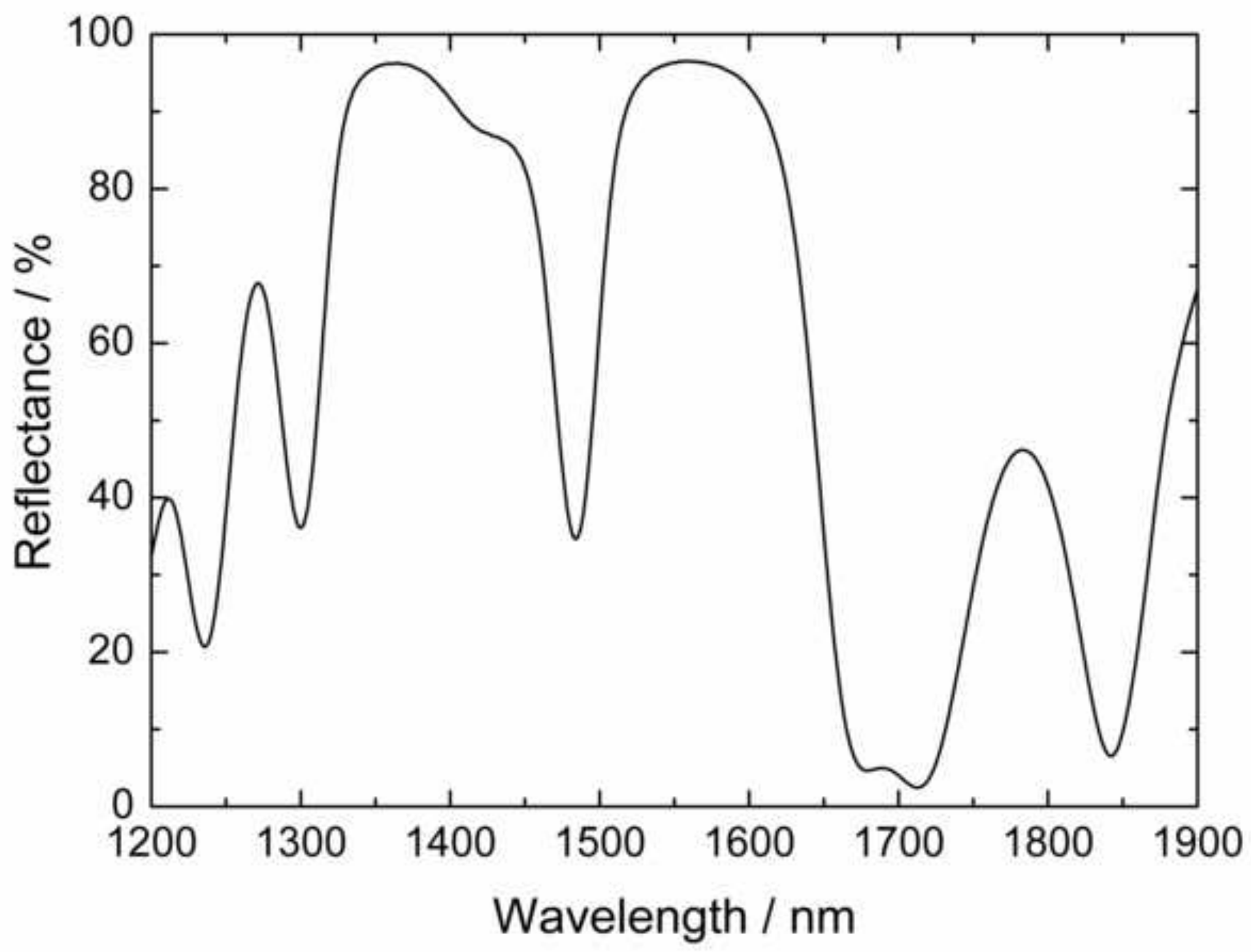




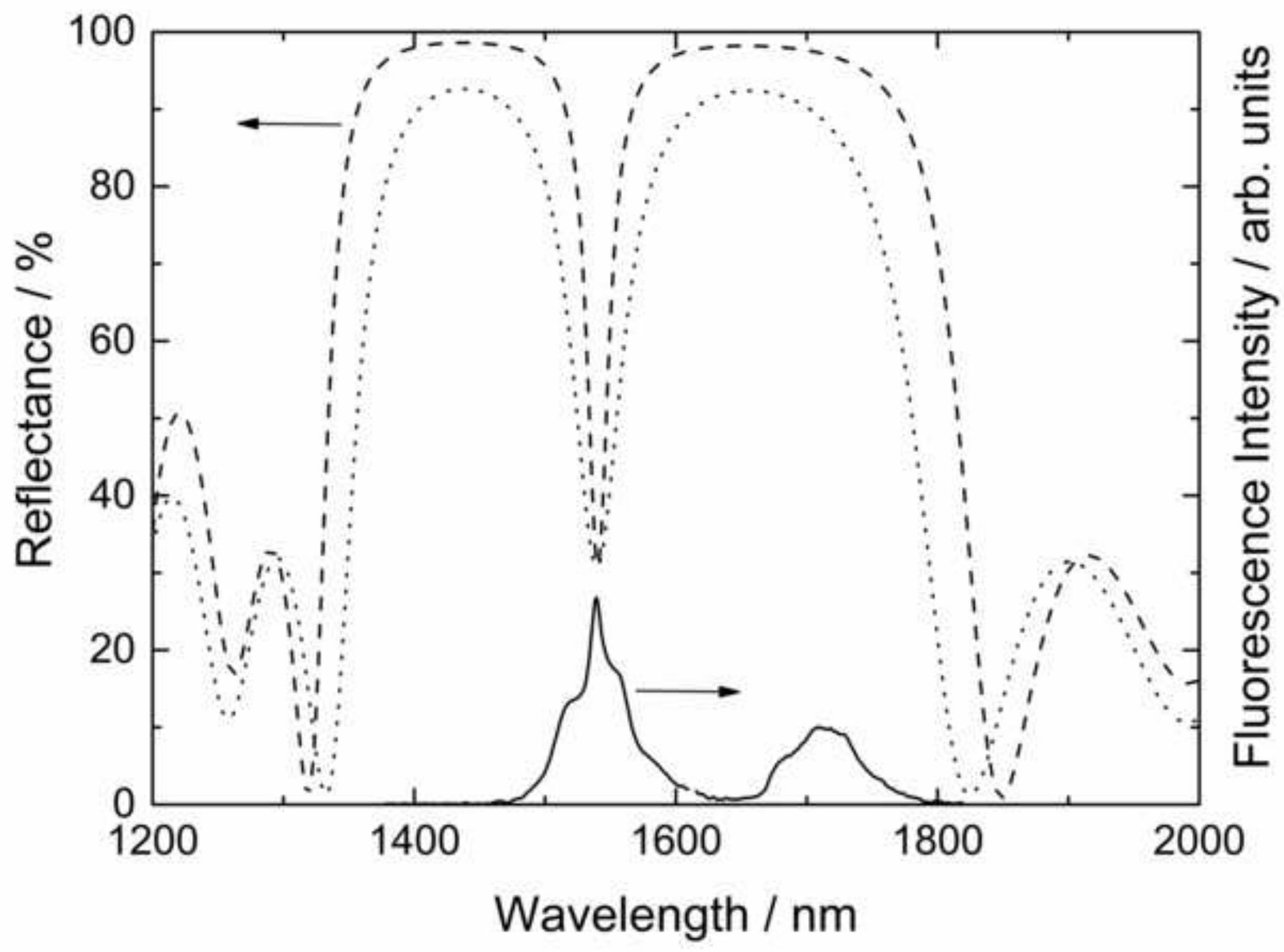




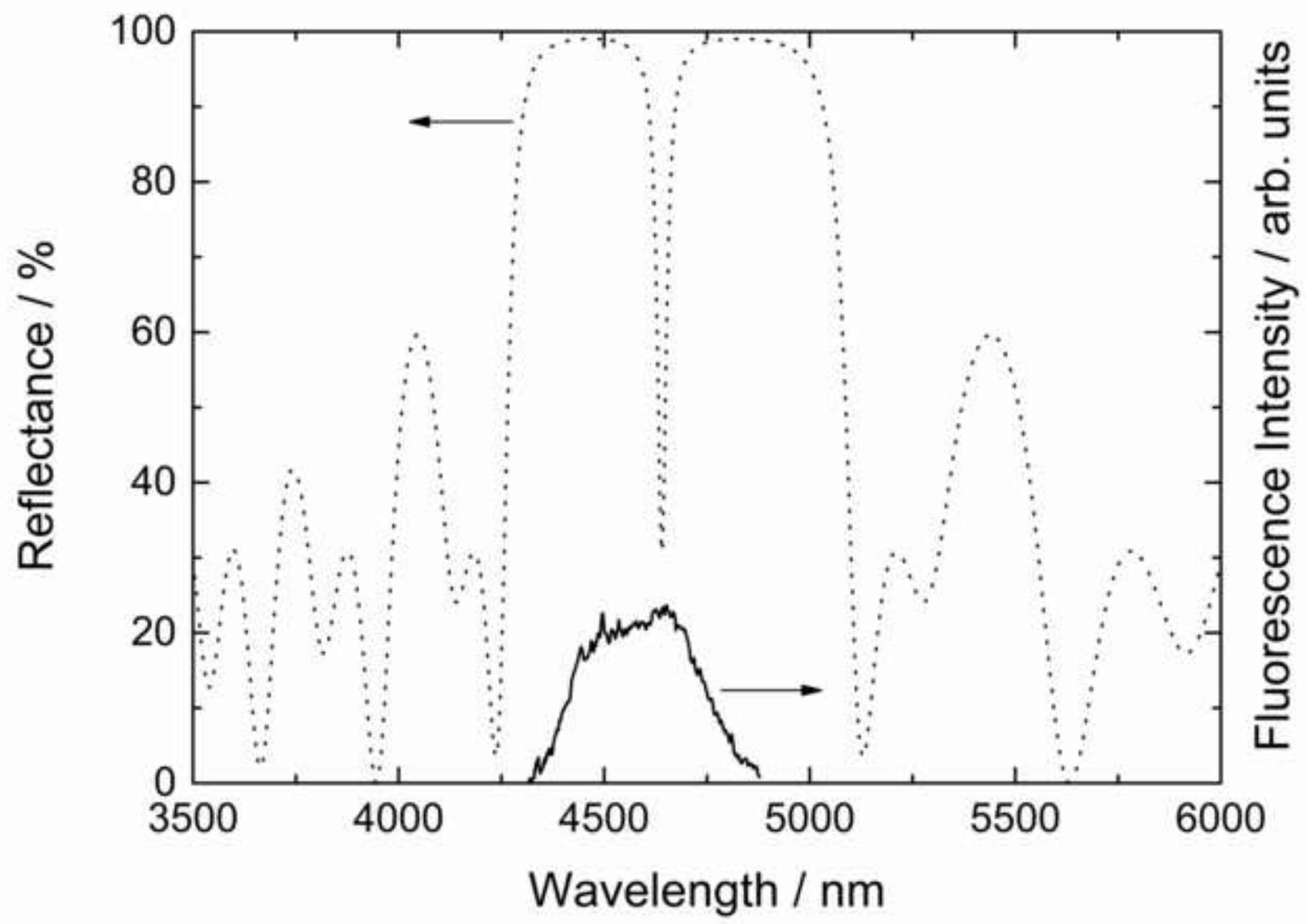

